\title{
Male Circumcision and HIV Prevention: Looking to the Future
}

\author{
Ronald A. Brooks · Mark Etzel · Lee E. Klosinski • \\ Arleen A. Leibowitz · Sharif Sawires · Greg Szekeres • \\ Mark Weston · Thomas J. Coates
}

Published online: 11 February 2009

(C) The Author(s) 2009. This article is published with open access at Springerlink.com

\begin{abstract}
Now that male circumcision has been shown to have a protective effect for men against HIV infection when engaging in vaginal intercourse with HIV-infected women, the research focus needs to shift towards the operational studies that can pave the way for effective implementation of circumcision programs. Behavioral research is needed to find out how people perceive the procedure and the barriers to and facilitators of uptake. It should also assess the risk of an increase in unsafe sex after circumcision. Social research must examine cultural perceptions of the practice, in Africa and beyond, including how likely uncircumcised communities are to access surgery and what messages are needed to persuade them. Advocates of male circumcision would benefit from research on how to influence health policy-makers, how
\end{abstract}

R. A. Brooks · M. Etzel - L. E. Klosinski .

A. A. Leibowitz - S. Sawires - T. J. Coates

Center for HIV Identification, Prevention, and Treatment

Services, Semel Institute, University of California, Los Angeles, CA, USA

S. Sawires · G. Szekeres · T. J. Coates

Program in Global Health, UCLA David Geffen School

of Medicine, Los Angeles, CA, USA

\author{
A. A. Leibowitz \\ Department of Public Policy, UCLA School of Public Affairs, \\ Los Angeles, CA, USA \\ M. Weston \\ Dorset, UK \\ R. A. Brooks ( $\square)$ \\ UCLA Center for Community Health, 10920 Wilshire Blvd. \\ Suite 350, Los Angeles, CA 90024, USA \\ e-mail: rbrooks@mednet.ucla.edu
}

best to communicate the benefits to the public, and how to design effective delivery models.

Keywords Male circumcision - HIV prevention . Implementation - Operational research

\section{Introduction}

Between 2005 and 2007, three randomized controlled trials in sub-Saharan Africa showed that male circumcision protects men against HIV infection during vaginal sex with women (Auvert et al. 2005; Bailey et al. 2007; Gray et al. 2007). In each of the trials, which were carried out in Uganda, Kenya and South Africa, infection rates among circumcised men were approximately $60 \%$ lower than among the uncircumcised control group. These findings, which supplemented results from earlier observational studies, demonstrated that male circumcision has the potential to sharply reduce HIV infection rates.

The three studies answered many, although not all, of the scientific questions about the impact of circumcision on health. It is still not known, for example, exactly how the process protects men against HIV. It is believed that uncircumcised men have a greater susceptibility to HIV due to the biological properties of the inner foreskin which contains a high concentration of Langerhans cells and other HIV target cells near the surface of the epithelium where there is no or minimal keratin protection (Quinn 2007; Weiss 2007). In addition, the inner foreskin is more susceptible to tears and abrasions which can facilitate infection with sexually transmitted diseases and subsequently HIV. Based on these factors, one possible explanation for the decreased susceptibility to HIV in circumcised men is the removal of the foreskin which results 
in the removal of the target cells for HIV infection (Quinn 2007; Weiss 2007). Furthermore, in circumcised men, the penis is thought to have a greater keratin barrier, thus providing additional protection from infection (McCoombe and Short 2006).

It is also still not clear whether circumcision protects men who have sex with men (MSM), or whether it protects against other diseases and conditions such as genital herpes (Millett et al. 2008). Many questions remain about how to implement the procedure beyond the trial sites. Following publication of the results, governments, funding agencies and communities have expressed strong interest in rolling out circumcision widely and rapidly. This interest has in many cases been backed by large allocations of resources. The success of such efforts in slowing infection rates will largely depend on the context in which they take placeindividuals and communities will have different perceptions of male circumcision and it is not yet known how they will respond to new circumcision programs or to the surgery itself. Mapping out this environment would help smooth the implementation process, promote uptake and render programs cost-effective.

In this brief think piece, which draws on the deliberations of a meeting on 'The Future Direction of Male Circumcision in HIV Prevention' held in November 2007 by UCLA's Center for HIV Identification, Prevention, and Treatment Services, in partnership with the US National Institute of Mental Health, we discuss the behavioral and social research that is needed to pave the way for rollout. We then outline some of the key policy questions facing those implementing male circumcision programs. This paper aims to set out a research agenda whose results will guide policy-makers as they attempt to capitalize on this potentially game-changing scientific breakthrough.

\section{Behavioral Research Agenda}

Many of those to whom new circumcision programs will be targeted will never have considered the procedure, as it is not part of their culture. The concept will therefore be a novelty and reactions hard to gauge without research.

Important questions remain about receptivity towards circumcision, as well as behavior after surgery is performed. In assessing receptivity, a better understanding is needed of individuals' perceptions of circumcision. Surveys conducted as part of the trials found that many men were concerned that the surgery would reduce their sexual pleasure. Others were concerned that becoming circumcised as part of an HIV prevention program could stigmatize them-the stigma surrounding HIV/AIDS has impeded prevention and treatment efforts since the start of the epidemic (Fortenberry et al. 2002; Vanable et al. 2006).
Still others were deterred by the cost of the procedure (post-trial uptake increased significantly as the cost fell). Establishing the barriers to circumcision for individuals in different communities is a vital first step in designing communication and education campaigns to promote its benefits.

The influencing factors on circumcision uptake also remain unclear. In some settings, education and persuasion by peers have promoted other forms of HIV prevention, such as condom use and sexual fidelity (Rietmeijer et al. 1996), but it is not known whether this will help increase uptake of male circumcision. In addition, recognizing that social networks and social norms are important determinants of individual behavior, it will be important to understand how social networks might influence decisions regarding male circumcision. The role of female partners also offers potential; women at the trial sites were keen for their partners to become circumcised (for reasons of health and hygiene), and targeting communications to women may be an effective way to reach reluctant men. If circumcision programs are to be sustainable, moreover, they need to include young boys. This will require ascertaining the barriers to and facilitators of parental acceptance of the process as well as factors affecting the attitudes of the youth themselves.

Related to the above is the packaging of circumcision services. It may be that including the procedure in general men's health packages helps reduce any potential stigma. Delivering the process in homes and in the presence of relatives, rather than in far-off clinics, could make it more of a social event rather than something an individual has to grapple with alone; this may also reduce stigma. Program designers would benefit from knowledge of how individuals are likely to respond to different delivery models, so the research need in this area is clear.

No randomized controlled trial has yet measured the effect of male circumcision on HIV transmission among men who engage in anal intercourse, including men who have sex with men (MSM). Some research suggests there may be a protective effect for the insertive partner, but for men who have sex with men too little is known about role variability (i.e., insertive versus receptive) to be sure whether this effect will persist among men who vary their sexual roles. A recent review of eighteen studies found "insufficient evidence" of a protective effect for MSM but called for further research (Millett et al. 2008). Behavioral research covering potential barriers should be a precursor of any future studies of the impact of circumcision on MSM.

The key question related to post-surgery behavior surrounds sexual disinhibition. Many commentators fear that men will see circumcision as fully protective against HIV and therefore engage in unsafe sex, thus reducing the 
protective effect of the surgery and putting themselves at risk of infection (Seed et al. 1995). Research at the trial sites found that no such disinhibition occurred, but it remains an open and important question whether the risk would be greater under less controlled conditions and with less intensive post-surgical counseling. Establishing the influences and messages that will prevent an increase in unsafe sex after circumcision will help ensure maximum HIV prevention benefits.

\section{Social Research Agenda}

Individual behavior, of course, is not the only determinant of whether circumcision programs will succeed. Social and cultural beliefs and traditions are of equal importance. Whether men are currently circumcised depends largely on the culture they are brought up in. Some communities circumcise, others do not. It is rare, for example, to find uncircumcised men in Muslim communities across the world.

Little research has been done to determine the social barriers to acceptance of male circumcision. It may be that some ethnic groups in Africa are unwilling to circumcise because the process is associated with groups they consider different or with groups they consider hostile and aggressive, but evidence on this is slim and designing programs and communication campaigns correspondingly difficult.

Acceptability of circumcision at the trial sites was very high (Bailey et al. 2007), suggesting the potential for strong uptake in communities that have traditionally refrained from circumcising. It is not yet known whether these findings apply elsewhere in Africa, however, and outside Africa knowledge of cultural perceptions is equally slim. Research among MSM in Peru has found a high willingness to participate in trials of male circumcision (Guanira et al. 2007). Among Hindus in India, contrary to expectations (being uncircumcised is seen by many as a mark of being a Hindu), a study has found high levels of acceptability of circumcision (Madhivanan et al. 2008). In the Caribbean, North America and Europe, on the other hand, little is known about cultural perceptions of the process. Without knowledge of the social barriers and facilitators of male circumcision, it will be impossible to tailor programs to their intended targets and therefore difficult to derive full benefit from them.

\section{Research and Program Implementation}

Research on how to influence decision-makers at all levels of health governance and on the factors that impact health policy would benefit advocates in their quest to roll out the procedure more widely. Advocates of male circumcision, including scientists, donors and civil society organizations, face an uphill task if they are to persuade key stakeholders to implement programs. Few African governments have expressed interest in offering free circumcision, with health ministries often deterred by costs (despite proven costeffectiveness) and concerns over disinhibition. In the US, a significant minority of state Medicaid programs do not currently fund routine male circumcision, with the consequence that infant circumcision rates are significantly lower in those states (Leibowitz et al. 2009). In both developed and developing world settings, according to a participant at the Future Direction of Male Circumcision in HIV Prevention meeting, there has been resistance among HIV prevention providers, who are more often trained in community behavior work than in surgical techniques and therefore sometimes distrust new medical technologies. Researchers at the randomized controlled trial in Kisumu, Kenya made concerted efforts to consult the government and the health sector throughout the trial and in its aftermath. Today the Kenyan government is fully committed to offering free voluntary male circumcision with assistance from donors (Family Health International 2008). Other governments, however, with stretched resources need to know the best balance for their HIV programs, and modeling exercises can help highlight the most effective combinations.

Once key decision-makers have been persuaded of male circumcision's merits, finding the right models for successful implementation will be an important next step. Research is needed, for example, to establish whether there will still be high uptake of surgery without the intensive counseling offered at the trial sites, and whether medical circumcision is favored over traditional forms of circumcision. It should be noted that some forms of traditional circumcision do not completely remove the foreskin, thus limiting the protective effect circumcision may provide against HIV infection (Brown et al. 2001). The optimum setting for surgery-be it in homes, clinics (whether mainstream or sexual health) or by mobile circumcision teams - is likely to vary in different communities; research can help identify the most promising approaches. A further open question is the relative weight that should be given to circumcision in efforts to prevent HIV compared with other activities such as education and communication campaigns, condom distribution programs, rollout of antiretrovirals and voluntary counseling and testing.

Communication campaigns around male circumcision, of course, should not be limited to influencing decisionmakers; research should also cover the most effective means of communicating its benefits to the public. Research into earlier successful media and education campaigns should inform those promoting circumcision, 
and messages should be tested before they are rolled out widely. Development of appropriate and effective messages should involve participation by community members, advocates and other stakeholders. Given that scientists and other advocates are not always best placed to develop successful communications campaigns, they should not shy away from seeking support from the private sector (e.g., from private health care companies and advertising firms) to help spread the message broadly and persuasively. Such support can also help scientists deal with the arguments of anti-circumcision lobbyists, who are often better prepared to get their point across in the modern media environment.

\section{Conclusion}

For the research priorities outlined above to come to fruition, a change of mindset is needed among funding agencies. Key funders such as the US National Institutes of Health, Centers for Disease Control (CDC), major global donors and national governments have traditionally focused their research resources on discovering new interventions rather than delivering existing ones. With male circumcision now proven to be effective in limiting HIV transmission, the focus needs to shift towards operational research, to the descriptive and observational studies that can support policy implementation. If the potential of male circumcision for HIV prevention is to be realized, behavioral, social and operational research must now move to center stage.

Open Access This article is distributed under the terms of the Creative Commons Attribution Noncommercial License which permits any noncommercial use, distribution, and reproduction in any medium, provided the original author(s) and source are credited.

\section{References}

Auvert, B., Taljaard, D., Lagarde, E., Sobngwi-Tambekou, J., Sitta, R., \& Puren, A. (2005). Randomized, controlled intervention trial of male circumcision for reduction of HIV infection risk: The ANRS 1265 trial. PLoS Medicine, 2, 1112-1122. doi: 10.1371/journal.pmed.0020298.

Bailey, R. C., Moses, S., Parker, C. B., Agot, W., Mcalean, I., Krieger, J. N., et al. (2007). Male circumcision for HIV prevention in young men in Kisumu, Kenya: A randomised controlled trial. Lancet, 369, 643-656. doi:10.1016/S0140-6736 (07)60312-2.
Brown, J. E., Micheni, K. D., Grant, E. M. J., Mwenda, J. M., Muthiri, F. M., \& Grant, A. R. (2001). Varieties of male circumcision. Sexually Transmitted Diseases, 28, 608-612. doi:10.1097/0000 7435-200110000-00007.

Family Health International. (2008). \$18.5 million grant makes male circumcision a top-tier HIV prevention strategy. Available at: http://www.fhi.org/en/AboutFHI/Media/081124_male_circumci sion_consortium.htm. Accessed on January 14, 2009.

Fortenberry, J. D., McFarlane, M., Bleakley, A., Bull, S., Fishbein, M., Grimley, D. M., et al. (2002). Relationships of stigma and shame to gonorrhea and HIV screening. American Journal of Public Health, 92, 378-381. doi:10.2105/AJPH.92.3.378.

Gray, R. H., Kigozi, G., Serwadda, D., Makumbi, F., Watya, S., Nalugoda, F., et al. (2007). Male circumcision for HIV prevention in men in Rakai, Uganda: A randomised trial. Lancet, 369, 657-666. doi:10.1016/S0140-6736(07)60313-4.

Guanira, J., et al. (2007). How willing are gay men to "cut off" the epidemic? Circumcision among MSM in the Andean region. In: Fourth International AIDS Society Conference on HIV pathogenesis, treatment and prevention, abstract WEAC102, Sydney.

Leibowitz, A. A., Desmond, K., \& Belin, T. (2009). Determinants and policy implications of male circumcision in the United States. American Journal of Public Health, (in press).

Madhivanan, P., Krupp, K., Chandrasekaran, V., Karat, S. C., Reingold, A. L., \& Klausner, J. D. (2008). Acceptability of male circumcision among mothers with male children in Mysore, India. AIDS (London, England), 22, 983-988. doi:10.1097/QAD. 0b013e3282ffde 52 .

McCoombe, S. G., \& Short, R. V. (2006). Potential HIV-1 target cells in the human penis. AIDS (London, England), 20, 1491-1495. doi:10.1097/01.aids.0000237364.11123.98.

Millett, G. A., Flores, S. A., Marks, G., Bailey, R. J., \& Herbst, J. H. (2008). Circumcision status and risk of HIV and sexually transmitted infections among men who have sex with men. Journal of the American Medical Association, 300, 1674-1684. doi:10.1001/jama.300.14.1674.

Quinn, T. C. (2007). Circumcision and HIV transmission. Current Opinion in Infectious Diseases, 20, 33-38. doi:10.1097/QCO. 0b013e328012c5bc

Rietmeijer, C., Kane, K., Simons, P., Corby, N., Wolitski, R., Higgins, D., et al. (1996). Increasing the use of bleach and condoms among injection drug users in Denver: Outcomes of a targeted community-level HIV prevention program. AIDS (London, England), 10, 291-298. doi:10.1097/00002030-1996 03000-00008.

Seed, J., Allen, S., Mertens, T., Hudes, E., Serufilira, A., Carael, M., et al. (1995). Male circumcision, sexually transmitted diseases, and risk for HIV. Journal of acquired immune deficiency syndrome, 8, 83-90.

Vanable, P. A., Carey, M. P., Blair, D. C., \& Littlewood, R. A. (2006). Impact of HIV related stigma on health behaviors and psychological adjustment among HIV-positive men and women. AIDS and Behavior, 10, 473-482. doi:10.1007/s10461-0069099-1.

Weiss, H. A. (2007). Male Circumcision as a preventive measure against HIV and other sexually transmitted diseases. Current Opinion in Infectious Diseases, 20, 66-72. doi:10.1097/QCO. 0b013e328011ab73. 